The tale of the gravitational waves has some way to rumble on yet. Next week, a meeting in Columbus, Ohio, organized by the Council for the Advancement of Science Writing, a panel of scientists and journalists, will search for "lessons learned by scientists and science writers involved with the BICEP2" story. What will these be?

The first thing to highlight is that such a thing as the Council for the Advancement of Science Writing even exists. Too many scientists dismiss the media and journalists as sloppy and unwilling to engage in both detail and ambiguity. In fact, there can be no branch of journalism as self-scrutinizing and anxious about its performance as that which covers science. It is hard to imagine political and sports reporters taking the time to discuss so thoroughly what (if anything) they did wrong after one of their stories went belly-up.

The (welcome) rise of the science blogger has fuelled this navelgazing. Some bloggers seem to spend most of their time criticizing other science writers, or at least debunking examples of what they regard as inferior science writing. But they do lots of good stuff too. Although traditionalists lament the decline of science coverage in the mainstream press, a terrific amount of analysis and comment, much of it very technical, is happening online under their noses.

Nature has a stake in discussions of the gravitational-waves story. Our news team was among those tipped off about the claim in advance. We were proud of our (extensive) coverage, both in print and online, at the time. We remain so now. Like most other news organizations, we reported the claims from the provisional paper accurately and, like almost all the coverage, were sure to include the caveat that the findings would need to be confirmed. That is not to claim that the press can be given a free pass on this. Its job is to ask questions after all. But it is not always possible for journalists - even the best science writers - to provide the answers.

What about the promised lessons for scientists? As we have pointed out before, researchers must not be afraid to be wrong. With hindsight they may feel they rushed to publish their claim too quickly, but professional science is a competitive and fast-moving field. The academic paper was cautious and the team's reaction to subsequent criticism seems constructive. Some may question the timing of the announcement, made when the paper was released on the Internet, not accepted

"As BICEP2 clearly demonstrates, most science is a work in progress." or published by a journal, but at least the evidence was there to examine. If the scientists and the media both largely acted properly, then what should be discussed at next week's meeting? It could do worse than start by screening the celebratory online video produced by California's Stanford University and released to accompany the announcement.

Scientists and journalists can include as many academic caveats as they like, but the sounds and images of champagne corks popping tend to render such statements of caution just that - academic.

There is a deeper issue here: science not by press conference but presented as an event. What in reality is a long, messy and convoluted process of three steps forward and two steps back is too easily presented as giant leaps between states of confusion and blinding revelation. At the heart of this theatre is the artificial landmark of a peer-reviewed paper. Fixed print schedules and releases to journalists under embargo (with or without champagne videos) help to lend the impression that the publication of a paper is the final word on a question - the end-of-term report on a scientific project that details all that was achieved.

As BICEP2 clearly demonstrates, most science is a work in progress. Which is surely good news for scientists, who remain useful, and for science writers, who will always have something to cover.

\section{Review rewards}

\section{Welcome efforts are being made to recognize academics who give up their time to peer review.}

\section{$\mathrm{H}$} ow many manuscripts is it reasonable for a scientist to peer review in a year? Many researchers would estimate two or three dozen; Malcolm Jobling, a fish biologist at the University of Tromsø in Norway, says that he has racked up more than 125 already this year. How do we know? A welcome movement is under way to publicly register and recognize the hitherto invisible efforts of referees.

Jobling's staggering total is revealed at Publons, a New Zealandbased start-up firm that encourages researchers to post their peerreview histories online (for an interview, see Nature http://doi.org/ wbp; 2014). Publons is not the only attempt to recognize and reward academics for their refereeing activity. As Nature noted last year (see Nature 493, 5; 2013), publishers are increasing their efforts to reward assiduous reviewers. The Nature journals give a free subscription to anyone who has refereed three or more papers in a year for them, and allow peer reviewers to download a statement of work. Similarly, science publisher Elsevier this year launched a system to formally recognize its peer reviewers, and to give rewards to 'outstanding reviewers' - those who have reviewed the most papers.

Unlike Publons, which hopes to establish a cross-publisher profile, the activities of individual publishers are restricted to their own platforms. But publishers are taking part in broader talks to establish standards to publicly record peer-review service in a researcher's ORCID (Open Researcher and Contributor ID) profile. Those discussions, under the auspices of the Consortia Advancing Standards in Research Administration (CASRAI), an international non-profit group, are also looking at ways to record other types of peer review - including reviews of grant

applications, conference abstracts, service as a journal editor and institutional benchmarking (for example, being on the panel of a national research audit such as the UK Research Excellence Framework).

Researchers could use their reviewer records to highlight their expertise for employers and government agencies. If enough information can be publicly revealed, it could shed more light on the average number and type of review undertaken by scientists, who increasingly complain that they are overwhelmed with peer-review requests.

The final direction of the drive to publicly record and reward peer review is far from clear. Publons - among others - hopes that there will be more cases of open, signed reviews (which will make it easy to recognize a referee's contribution). Yet the majority of pre-publication reviews remain private: many researchers are uncomfortable about being publicly revealed as the author of a critical review because of the fear of subtle reprisals in other areas of their career. Unless this culture shifts, efforts will stay focused on allotting credit for reviews whose text and author remain secret.

Recording the number of reviews is only the start. A well-considered review that substantially improves a paper can take days - whereas a sloppy reviewer could dash off assessments of many papers in a few hours. So the next challenge in publicly recognizing peer review will be to find a way to assess quality. Many journal editors already have an informal idea of their 'good' and 'bad' reviewers, which in some cases can be quantified by response time. But these judgements are not usually shared with colleagues, and may differ from one editor to another. Lutz Prechelt, an informatics researcher at the Free University of Berlin who is advising Elsevier on its programme, has suggested that both authors and editors could be asked to mark the helpfulness and timeliness of a review. But it will be important to ensure that the benefits of this system are not drowned by the bureaucracy involved.

Efforts to publicly recognize peer review are

D NATURE.COM To comment online, click on Editorials at: go.nature.com/xhunqv still in their infancy. But as attempts to acknowledge and reward a crucial role, they should be applauded. 